\title{
Process Support of Business and IT Management in Czech Companies
}

\author{
Renáta Kunstová \\ University of Economics, Faculty of Informatics and Statistics \\ W. Churchill sq. 4, Prague 3, Czech Republic \\ kunstova@vse.cz
}

\begin{abstract}
Defined, monitored and measured processes are significant preconditions for a well process-managed company. They are also important conditions for delivering information technology resources as services. The model, which is based on service management, is described at the beginning of this paper. The main part of this paper focuses on the results of an extensive survey. This survey dealt with an investigation into whether companies operating on the Czech market have defined business and IT processes, and if these processes are monitored, measured and continuously optimized.
\end{abstract}

Keywords: Model of management, business processes, IT processes, IT services.

\section{Introduction}

Information systems, and information and communication technologies (IS/ICT, or in short IT) are important factor for successful companies. Their purpose is to support business activities. The alignment between business needs and IT capabilities became a main area of top management concern because if IT supports business strategies and processes, then IT brings competitive advantage. The business/IT alignment depends on many factors, such as the level of communication between business and IT managers, their cooperation in strategic planning, definition of IT and business metrics, which are monitored etc. $[12,16]$ The business/IT alignment is also influenced by a current trend to solve everything through services. Software as a Service, Infrastructure as a Service, Platform as a Service etc. are new business models, which changed the usual approaches to the management of enterprise IS/ICT. Service-oriented approaches increase commitment to process orientation, and put emphasis on managing the relationship between business and IT [17]. Companies need to satisfy the following preconditions to take full advantage of new service-oriented models:

- management of business processes,

- management of IT processes,

- delivering IS/ICT resources through IT services.

The members of the Department of Information Technology at the University of Economics in Prague deal with the management of enterprise IT. The service-oriented 
approach to IT and business management is illustrated in the SPSPR model, see Fig. 1. The acronym "SPSPR" is formed from the first letters of key words: Strategy Process - Service - Process - Resource. These words refer to layers of the model. The layers of this model can be assigned to appropriate levels of management. The strategic management layer and the business processes layer belong to the strategic level of management. The IT Services layer corresponds to the tactical level of management. The IT processes layer and IT Resources layer relate to the operational level of management.

The SPSPR model was first published in 2001 [21]. On the basis of our experiences with its implementation, the model was continuously updated from that time. The implementation of IT services, according to the SPSPR model, includes the following phases:

- definition of processes, services and resources and their metrics,

- operational management of processes, services and resources,

- monitoring and measuring of processes, services and resources,

- optimization of processes and services according to the business strategy, and to the consumption of resources.

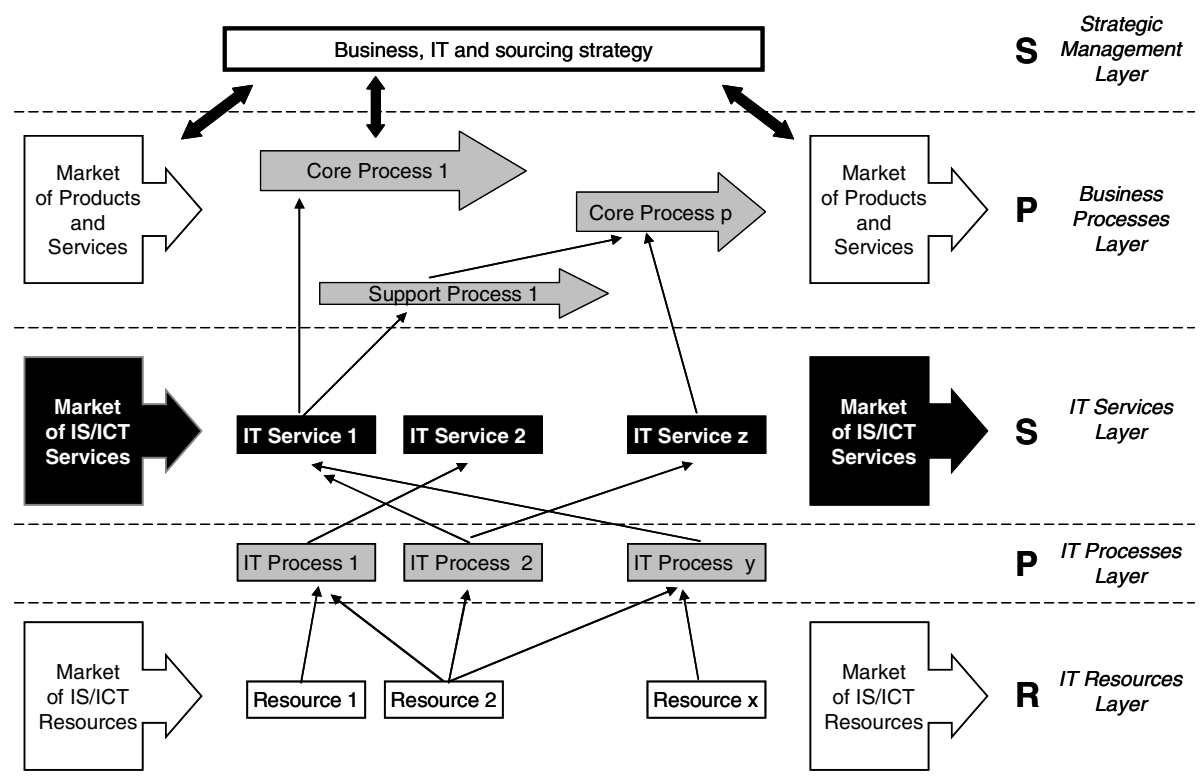

Fig. 1. The SPSPR model

The basic principle of the SPSPR model is a linking of business processes and IT processes through IT services. The other principle is that business and IT processes are measured and monitored. This allows the quick identification of emerging issues and allows management the opportunity to react immediately and to change the performance of processes. From a top down view it is seen that business strategy is realized through business processes, business processes are executed by IT services, 
IT services are managed by IT processes and IT processes use IT resources. The SPSPR model contributes to business/IT alignment.

Within our current grant project, "Advanced Principles and Models for Enterprise ICT Management", we are working on the proposal of the overall conceptual model for corporate performance management. The SPSPR model is one of the fundamental elements. The conceptual model follows on our previous work (for instance 1, 2, 3, 9, $10,13,14,15,19,20$ and 22), current business requirements and the results of our surveys.

As mentioned above, the important precondition of a well managed service-oriented company is a process-oriented management of business and IT processes. Within the survey we verified if companies operating on the Czech market have implemented process management. The results of this survey are discussed in this paper.

\section{Using of IT to Support Business}

As the implementation of process-oriented management relies on the use of IT in companies [5, 18], we checked the status of IT in Czech companies on the basis of statistical data. We used the data which is freely available on the website of the Czech Statistical Office [4]. We found that although the trend of the use of IT is growing long-term in Czech companies, only two thirds had a corporate computer network, less then a quarter of companies use the electronic exchange of structured data within business processes between companies and fifteen percent of companies regularly share business information electronically with suppliers or customers. In comparison with EU27 data, also published at [4], the Czech Republic is below the EU27 average in most indicators (see Fig. 2).

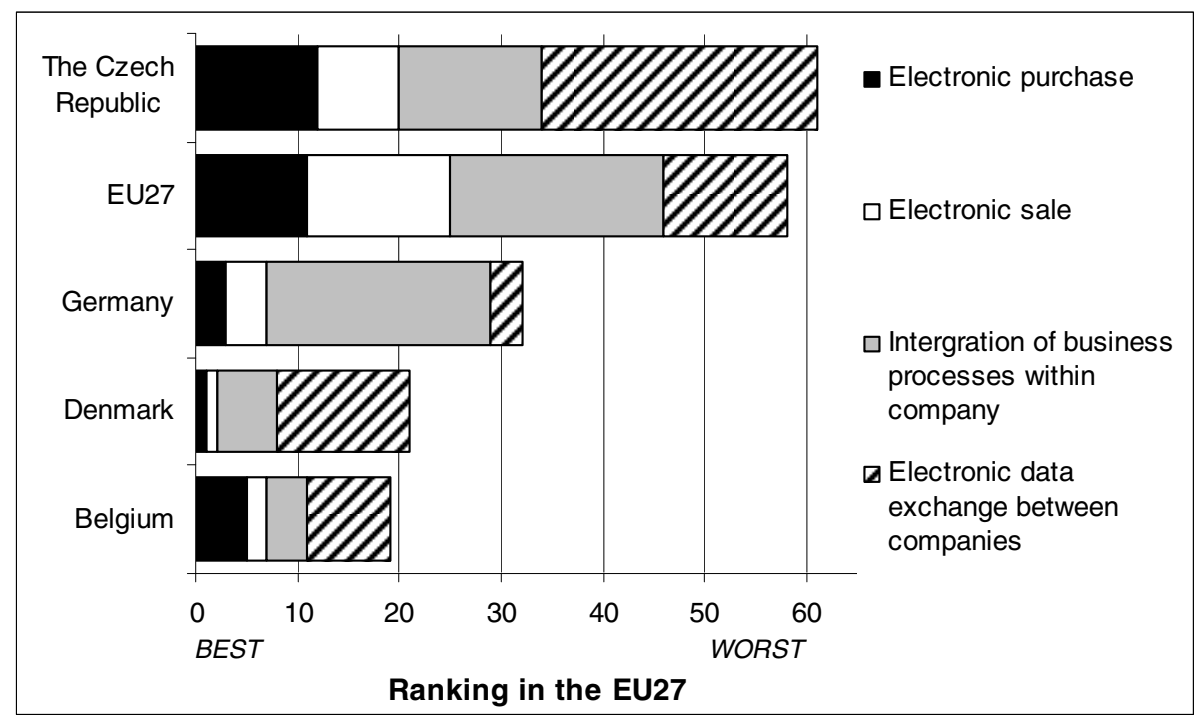

Fig. 2. Countries according to the sum of the rank position in the selected indicators 
The indicators published above reflect the percentage of the total number of companies in the country. Indicator values were ranked in descending order. This means that the shorter the column on the graph, the better the ranking. Belgian companies present the most extensive use of IT in business. Denmark ranks first in electronic purchases and sales. Third place is occupied by Germany. The Czech Republic ranks nineteenth. It is below the EU27 whose position is 14. Further details about the ranking of the Czech Republic in comparison to other European countries are in [6, 7 and 8].

From this comparison it is evident that the Czech Republic does not have a good standing among other countries of the European Union. On the other hand, the realization of electronic purchases, electronic sales, electronic data exchange and the integration of business processes demonstrates the existence of processes in companies. Therefore, we decided to realize our own survey which will provide information about features of processes such as monitoring, measurement, managing and optimization.

\section{Survey Methodology}

As the management of business and IT processes is a one of the conditions for successful management of services, our survey focused on processes. The goal of our survey was to investigate, if companies operating on the Czech market are interested in their processes, if they have their processes described and implemented in day-today operations and if these processes are managed, measured and optimized.

The basic structure of our investigation is shown in Fig. 3. In accordance with the basic principles of the SPSPR model, we differentiated between business processes (the main processes supporting the business goals of the company) and IT processes (the processes of the company's own management of IS/ICT). A company which would agree with these statements for business and IT processes meets the assumptions for providing IT as a service and business/IT alignment.

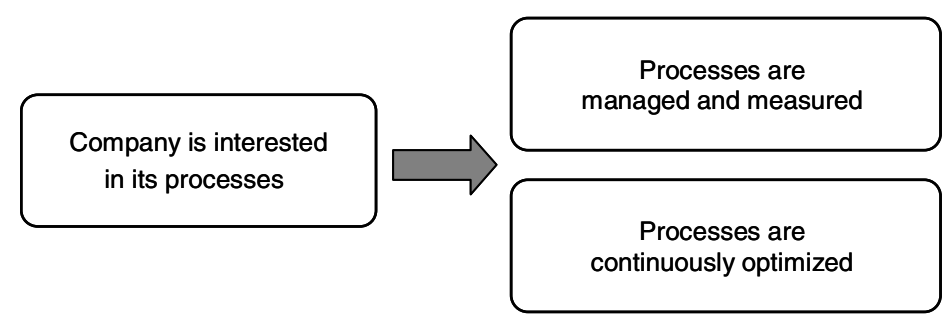

Fig. 3. Basic structure of investigation

The survey hypotheses were as follows:

1. Hypothesis: If a company has specified business processes, then it has specified IT processes too.

2. Hypothesis: If a company has specified business processes, then it manages, measures and optimizes them.

3. Hypothesis: If a company has specified IT processes, then it manages, measures and optimizes them. 


\section{Survey Realization}

The survey was a starting the point of our following work so it had to extensive and national in nature. We chose a professional company to receive a large sample of quality data. The questionnaire contained questions to verify the hypotheses related to our work on a conceptual model for corporate performance management. Hence, this paper focuses only on a part of the survey. The survey was realized in October 2010 and the survey data was analyzed in 2011.

\subsection{Data Collection}

On the basis of the offers submitted by several professional companies, we contacted Ipsos Tambor, s.r.o. (http://www.ipsos.cz). This company is a part of an independent international company (http://www.ipsos.com), which has offices in 66 countries and ranks fifth among global research companies.

The company chosen recommended using the CATI (Computer-Assisted Telephone Interviewing) method for data collection. This method increases the accuracy and comparability of data collected, and the speed and efficiency of their collection. All interviews are recorded and a research company can listen to these interviews.

The company ensures the highest quality of interviewing through control mechanisms and practices. The operators of the professional company first contacted every respondent and asked them for their consent to participate in the survey. Then respondents received a questionnaire and answered the questions in a controlled phone call. The operators had the questionnaire available with detailed instructions.

\subsection{Data Sample}

The data sample was based on statistical data published by the Czech Statistical Office with the following demands.

1. The survey had to cover all industry sectors, except for companies operating in the IT industry. Among the industry sectors, in which the company operates, the following should be preferred: banking and insurance, telecommunications, utilities, government and public services. These companies, highly dependent on IT, should be about a third of all surveyed companies.

2. The survey has to involve only companies with the following number of employees: $10-49,50-249,250$ and more. According to the expected use of our work, we preferred companies with 50 - 249 employees.

Companies were selected by quota sampling. The total number of surveyed companies was limited by the purchase price of the professional data collection. The survey involved respondents from 600 companies operating on the Czech market. The basic characteristics of these companies were very different. 


\subsection{Questionnaire Structure}

The questionnaire was divided into six sections. The author focuses only on the first and the third section, which are related to this paper. The first section of the questionnaire contained questions designed to detect essential characteristics of the company and its respondent. Respondents always marked one item from the list.

We discovered the following characteristics:

- How many employees does your company have?

- In which industry sector does your company operate?

- What is your company's establishment?

- What is your job position?

The third section of the questionnaire contained the main research questions. The first set of questions related to business processes, the second set of questions related to IT processes. The questions and possible answers are shown in Table 1.

Table 1. Research questions and possible answers

\begin{tabular}{ccc}
\hline & 1st set of questions & 2nd set of questions \\
\hline Question 1 & $\begin{array}{c}\text { How are business processes } \\
\text { specified (i.e. defined and } \\
\text { described) within a company? }\end{array}$ & $\begin{array}{c}\text { How are IT processes specified } \\
\text { within a company? }\end{array}$ \\
Answer 1.1 & $\begin{array}{c}\text { Processes are not specified. } \\
\text { Answer 1.2 }\end{array}$ & $\begin{array}{c}\text { Processes are not specified. } \\
\text { Parts of processes are specified. }\end{array}$ \\
Answer 1.3 & Processes are fully specified. & Processes are fully specified. \\
\hline Question 2 & Are business processes managed & Are IT processes managed and \\
& and measured? & measured? \\
Answer 2.1 & Yes & Yes \\
Answer 2.2 & No & No \\
\hline Question 3 & Are business processes & Are IT processes continuously \\
& continuously optimized? & optimized? \\
Answer 3.1 & Yes & Yes \\
Answer 3.2 & No & No \\
\hline
\end{tabular}

The respondents received Question 2 and 3 only if they had chosen the second or third answer on Question 1.

\section{Survey Results}

We received the data collected in the form of a Microsoft Excel table. The analysis was performed using statistical functions. Data was analyzed in several phases. At first, the absolute and relative frequency of individual characteristics was measured. Then the analysis of processes according to basic characteristics was performed. At the end dependences were examined by contingency tables. The strength of the 
correlation between the features analyzed was calculated by C-Pearson, V-Cramer and Cohen's "kappa" coefficients.

\subsection{Analysis by Company Size}

The total number of participating companies was 600. The largest group of respondents, $63 \%$ (in absolute numbers it was 380 companies), was from mid-size companies with 50 - 249 employees. Twenty percent of respondents (120 companies) were from companies with 250 and more employees. The remaining $17 \%$ of respondents were from small companies with 10 - 49 employees (100 companies).

Ninety six respondents $(16 \%)$ answered that their company has no specified business processes and 134 respondents $(22 \%)$ answered that their company has no specified IT processes. The largest group were companies with partly defined processes (business processes - 282 companies, 47\%; IT processes - 318 companies, $53 \%)$. Two hundred and twenty two companies (37\%) have fully specified business processes, $25 \%$ (148) of companies have fully specified IT processes.

With the increasing number of employees (see Fig. 4), the probability that the processes are not specified significantly decreases. This trend appeared for business and IT processes too.
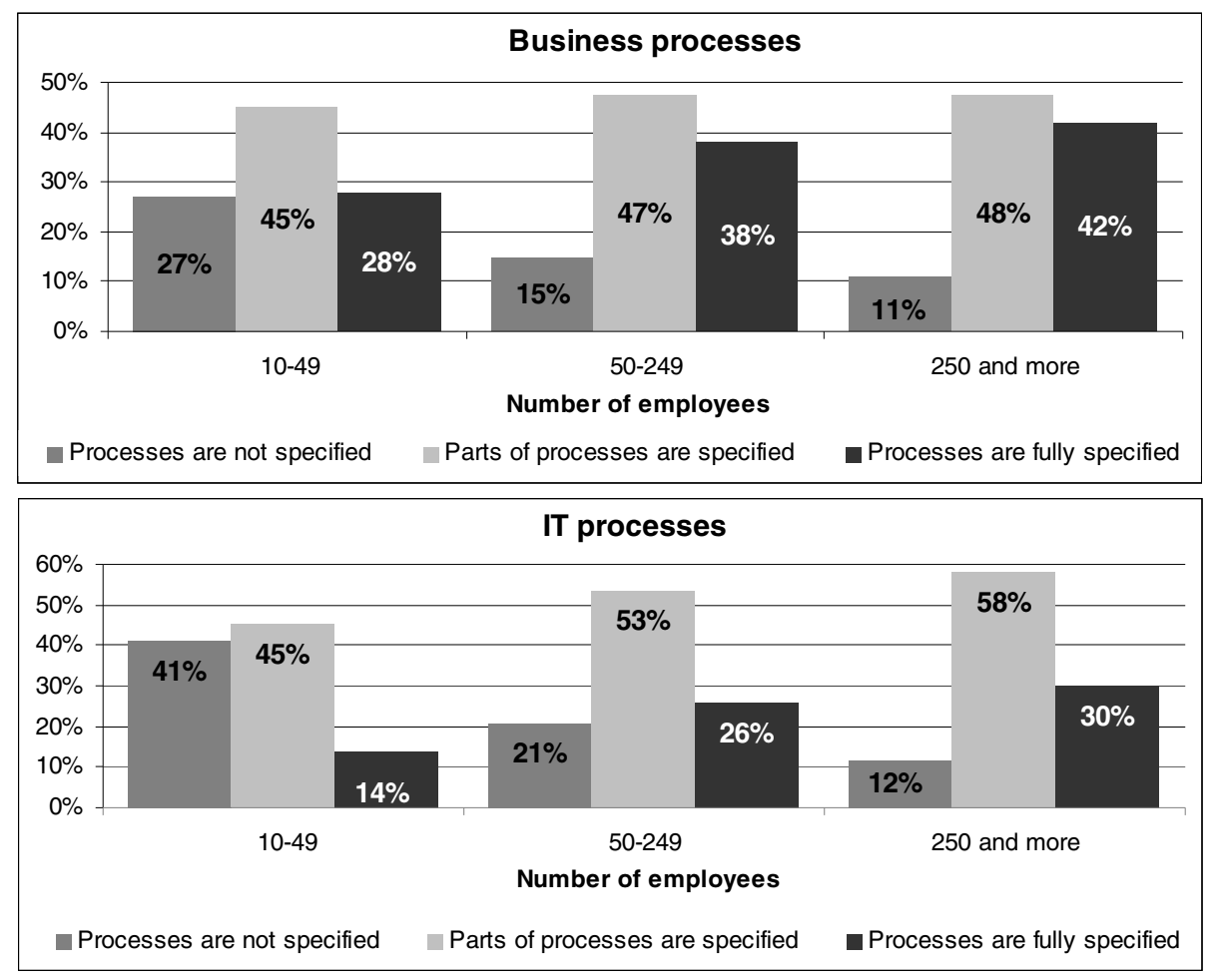

Fig. 4. Processes specification according to number of employees 


\subsection{Analysis by Industry Sector}

Due to the fragmentation of companies in different industry sectors, the numbers of companies from various industry sectors were accumulated according to their dependence on IT. The number of companies which are highly dependent on IT (banking, insurance, utilities, telecommunication services, government and public services) was 204 (34\%). The number of companies with medium dependence on IT (manufacturing, retailing, accommodation and catering, real estate, healthcare, wholesale business) was 202 (34\%). The number of low dependence on IT companies (construction, education, culture and recreation, mining industry, forestry and fishing, agriculture) was 194 (32\%).

The survey did not establish a link between the level of a company's dependence on IT and whether the company has specified processes and / or their parts. The number of companies in each group was almost the same, the percentage distribution was very similar too - see Fig. 5 .

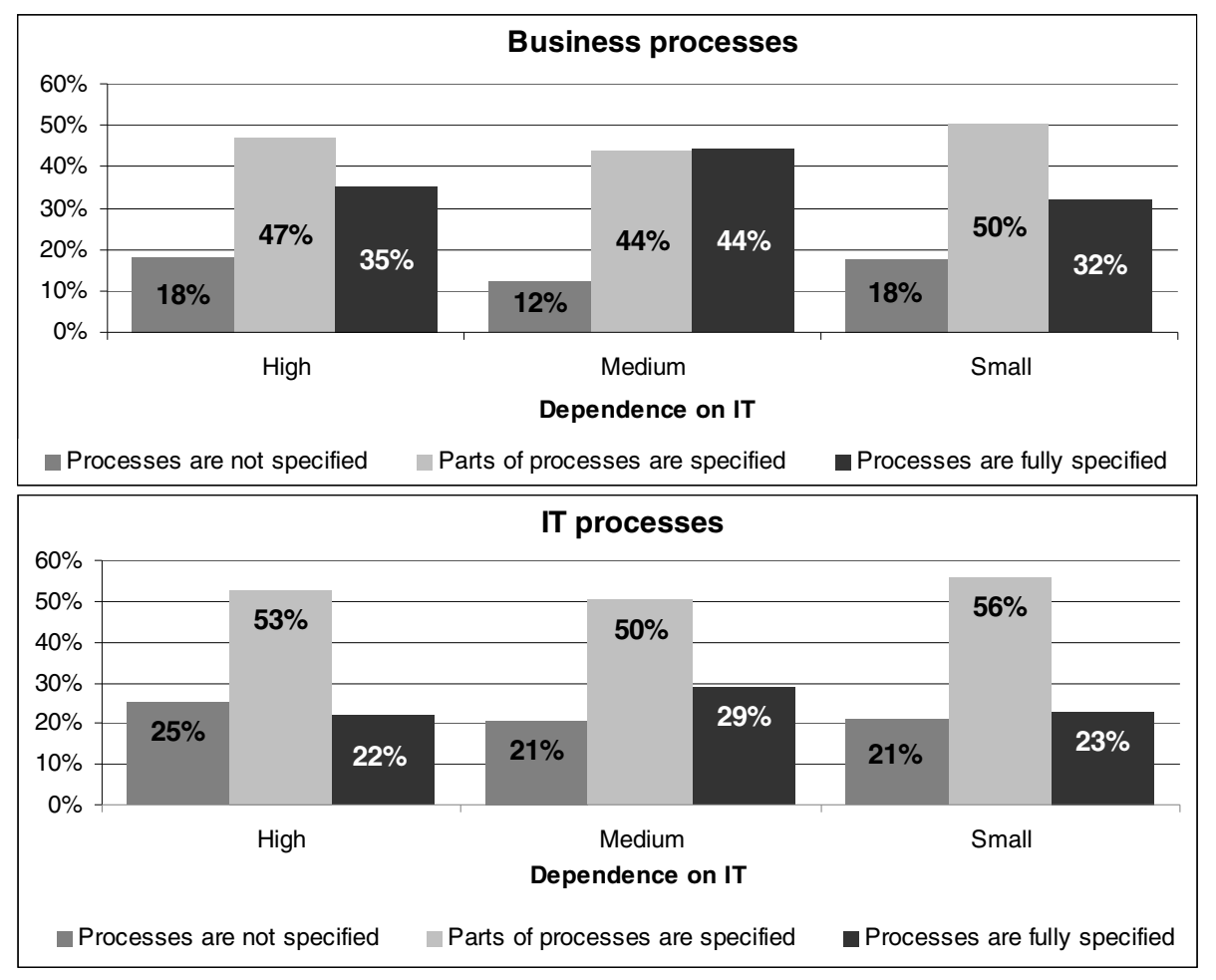

Fig. 5. Processes specification according to industry sector - dependence on IT 


\subsection{Analysis by Company's Establishment}

The largest group of companies were companies founded in the Czech Republic without offices abroad $-488(81 \%)$, affiliates of multinational companies presented $79(13 \%)$ of companies and the remaining 33 (6\%) companies were Czech companies now with offices abroad - see Fig. 6.
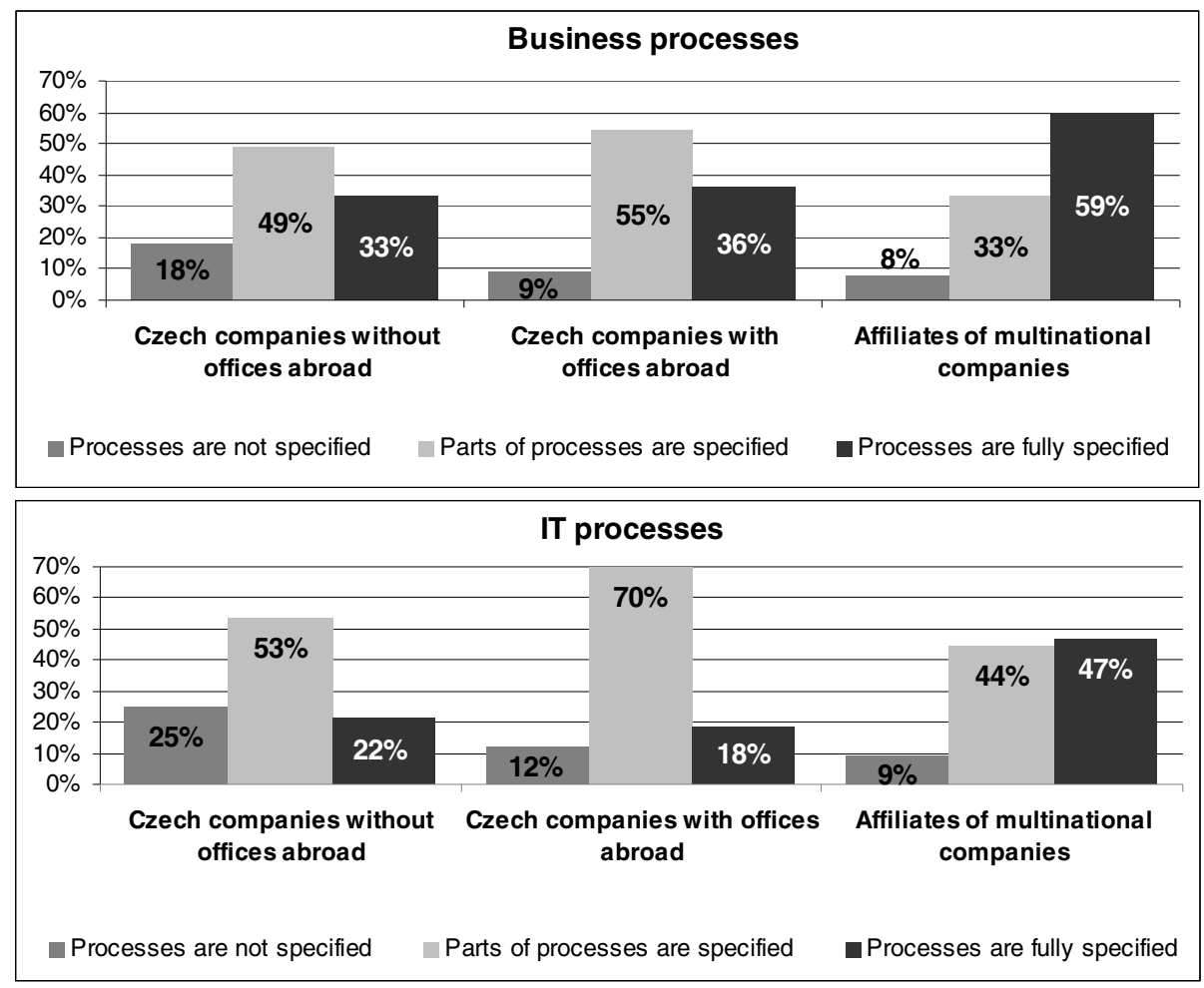

Fig. 6. Processes specification according to company's establishment

Respondents from multinational companies often answered that their company has business and IT processes fully specified. Czech companies with offices abroad have parts of processes specified. Czech companies without offices abroad also have most often parts of processes specified, but the percentage distribution is lower. The comparison of business processes against IT processes within each group by company establishment show that business processes are more often fully specified and IT processes are more often specified in parts. The worst situation was in Czech companies without offices abroad. 


\subsection{Analysis by Management Level of Processes}

Eighty four percent of all companies surveyed (47\% of companies which have defined parts of the business processes, and $37 \%$ companies with fully defined business processes, i.e. 504 companies) were also examined to find whether their processes are measurable, managed and continuously optimized. Twelve percent of these answered that they have defined business processes and / or their parts, but nobody measures, manages or optimizes them. The companies more often continuously optimize business processes than they measure and manage them (see Fig. 7).

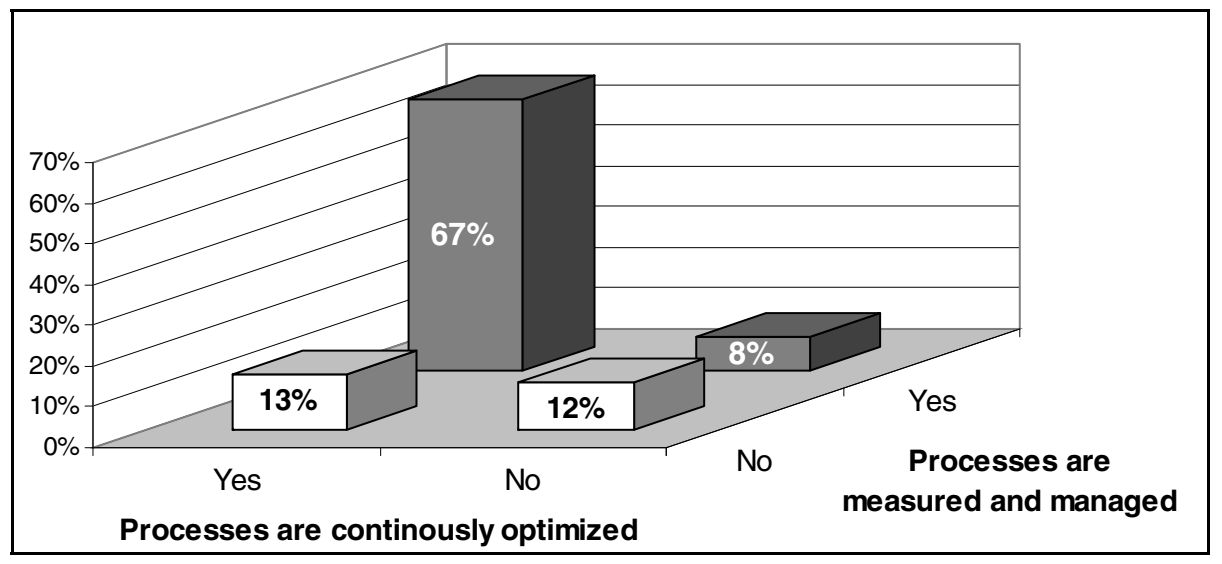

Fig. 7. Division of companies according to the conducting of business processes

Questions relating to the measurement and optimization of IT processes were referred only to 466 respondents (53\% of companies which have defined parts of the IT processes and $25 \%$ of companies with fully defined IT processes) - see Fig. 8 . The percentage of continuously optimized, measured and managed IT processes is lower than business processes. The IT processes are three times more often continuously optimized than measured and managed.

It could be assumed that the measured, managed and continuously optimized processes will be applied mainly by those companies in which the sector is highly dependent on IT, but the survey results did not support that implication. No significant dependences were found upon investigation of the relationship between the characteristics of the companies and the conducting of the company's processes. The number of employees in the company, and the company's dependence on IT, was distributed uniformly.

An increasing trend was seen depending on the company's dislocation. Companies with offices abroad have a higher percentage of measured, managed and optimized processes, and companies which are a part of a multinational company have an even higher percentage. 


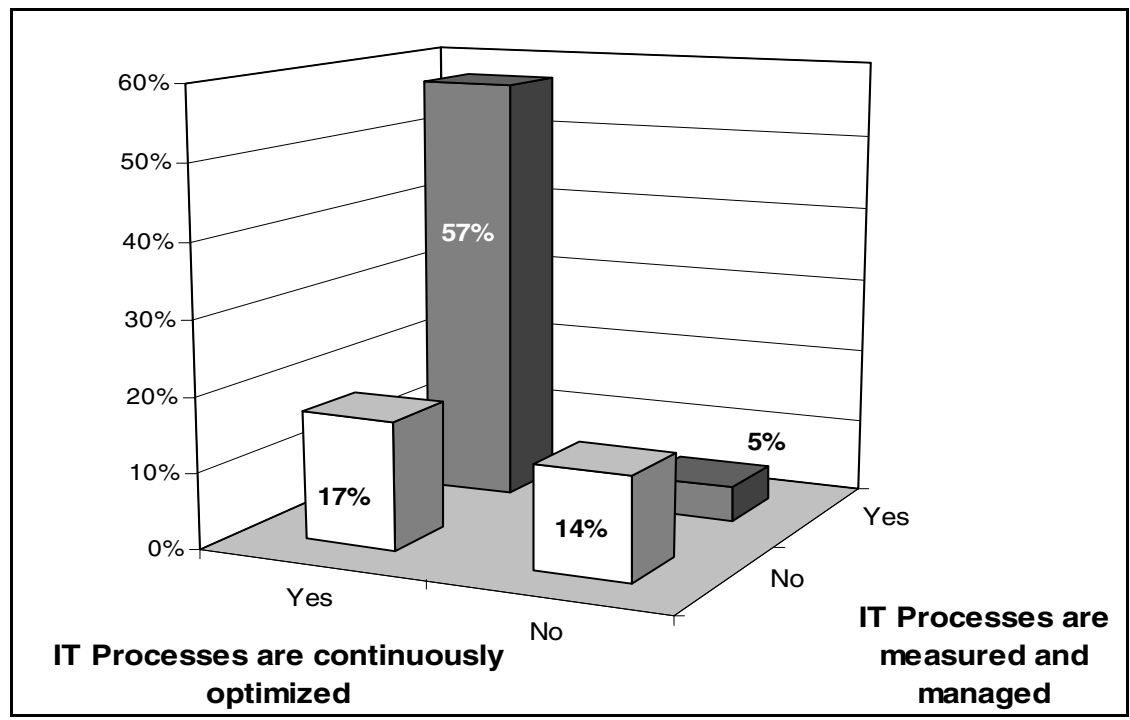

Fig. 8. Division of companies according to the conducting of IT processes

\subsection{Analysis of Relations between Business Processes and IT Processes}

This phase of the analysis was started by comparing the relative frequency, of the characteristics of business and IT processes observed. The co-occurrence of single characteristics is demonstrated in Table. 2. The largest percentage of all combinations is partially specified business and IT processes $(35 \%)$. The smallest percentage $(1 \%)$ is the combination of fully specified business processes and unspecified IT processes.

Table 2. Percentage distribution observed characteristics of business and IT processes

\begin{tabular}{lccc}
\hline & $\begin{array}{c}\text { IT Processes are } \\
\text { not specified }\end{array}$ & $\begin{array}{c}\text { Parts of IT } \\
\text { processes are } \\
\text { specified }\end{array}$ & $\begin{array}{c}\text { IT Processes are } \\
\text { fully specified }\end{array}$ \\
\hline $\begin{array}{l}\text { Business processes are } \\
\text { not specified }\end{array}$ & $12 \%$ & $4 \%$ & $1 \%$ \\
\hline $\begin{array}{l}\text { Parts of business } \\
\text { processes are specified }\end{array}$ & $7 \%$ & $35 \%$ & $5 \%$ \\
\hline $\begin{array}{l}\text { Business processes are } \\
\text { fully specified }\end{array}$ & $3 \%$ & $14 \%$ & $19 \%$ \\
\hline
\end{tabular}

Inter-rater reliability was determined by Cohen's kappa coefficient. The results investigated are in Table 3 . The most significant agreement is in the relation between the managing and measuring of business and IT processes. If business processes are managed and measured, IT processes are managed and measured too. This dependency was confirmed by the chi-square test with Pearson's contingency coefficient, 0.53 (the maximum value is 0.707 ), and Cramer's V coefficient, 0.62. 
Table 3. Reliability determined by Cohen's kappa coefficients

\begin{tabular}{lc}
\hline Validated addiction & kappa \\
\hline Defining, partially defining or non defining of business and IT processes & 0.46 \\
Managing and measuring of business and IT processes & 0.61 \\
Optimizing of business and IT processes & 0.56 \\
Managing / measuring and optimizing of business processes & 0.38 \\
Managing / measuring and optimizing of IT processes & 0.41 \\
\hline
\end{tabular}

The weak rate agreement is within the conducting of business processes $(0.38$ kappa). The survey had the following finding: if the company manages and measures business processes, it does not mean that business processes are also optimized. Other measures of dependence are in the range of kappa, $0.41-0.56$. It is interpreted as moderate agreement [11].

\section{Discussion}

The hypotheses were tested on the data sample from six hundred respondents. We investigated the probability of confirming these hypotheses, and a relationship with external factors arising from the characteristics of companies and respondents.

The first hypothesis, "If a company has specified business processes, then it has specified IT processes too", was proved with Cramer's V coefficient, 0.50 and Pearson's coefficient, 0.58 (the maximum value is 0.82 ). The dependence was reduced by the factors that companies usually have fully or partially specified business processes rather than IT processes. A significant difference is shown between the Czech companies and affiliates of foreign corporations. Multinational companies had specified business and IT processes rather than Czech companies.

The second hypothesis, "If a company has specified business processes, then it manages, measures and optimizes them", was confirmed by 336 (i.e. 56\%) of the companies. The third hypothesis, "If a company has specified IT processes, then it manages, measures and optimizes them", was confirmed by 266 (i.e. 48\%) of the companies.

Companies which confirmed all three hypotheses have, with a high probability, implemented process management and therefore they are prepared to provide IT as a service, or they already do it this way. The number of these companies was 259 (i.e. $43 \%$ ). These companies were Czech company without offices abroad, with $50-250$ employees, operating in different industry sectors.

\section{Conclusion}

Current trends in the business environment give attention to services. A serviceoriented approach emphasises on the management of processes. Our research focused on the level of process-oriented approaches in Czech companies. We realized an extensive national survey for this purpose. 
Although this study was limited to the Czech market, the research provides sufficient data to show that Czech companies converge slowly on process management. The implementation of the SPSPR model is possible but on the basis of the results of the described survey, we should focus on the specified group of companies.

An important conclusion arising from the survey is that the systematic management, measurement and optimization of business processes are far from usual in Czech companies. If a company is engaged in business processes, it does not mean that it has implemented process management in the area of IT. The implementation of IT services will require these companies to change their approach to the management of the business and IT processes.

Acknowledgments. This paper was supported by the "Advanced Principles and Models for Enterprise ICT Management" grant, from the Czech Science Foundation under the number P403/10/0092.

\section{References}

1. Basl, J., Gála, L.: The Role of ICT in Business Innovation. In: IDIMT-2009 System and Humans - A Complex Relationship, pp. 67-76. Trauner, Linz (2009)

2. Bruckner, T.: Who is responsible for requirements definition for ICT services and which SLAs are defined in Czech businesses (survey results). Systémová Integrace 17(4), 125-147 (2010)

3. Buchalcevová, A.: Research of the Use of Agile Methodologies in the Czech Republic. In: Barry, C., Conboy, K., Lang, M., Wojtkowski, G., Wojtkowski, W. (eds.) Information Systems Development - Challenges in Practice, Theory, and Education, vol. 1, pp. 51-64. Springer, New York (2009)

4. Czech Statistical Office. Public database, http://www.czso.cz/eng/redakce.nsf/i/information_society

5. Doucek, P.: Dynamic Modelling of the Software Development Process. Cybernetics and Systems 27(4), 403-410 (1996) ISSN 0196-9722

6. Doucek, P.: Resources in ICT - ICT Effects on GDP. Jindřichův Hradec 08.09.2010 10.09.2010. In: IDIMT-2010 Information Technology - Human Values, Innovation and Economy, pp. 97-105. Trauner, Linz (2010)

7. Doucek, P., Nedomová, L.: ICT and Economy - Slovenia and Czech Republic Experience. Portorož 23.03.2011 - 25.03.2011. In: Organizacija prihodnosti - Future Organization (CD-ROM), pp. 268-278. Univerzita v Mariboru, Maribo (2011)

8. Doucek, P., Nedomová, L., Novotný, O.: How ICT Affect the Czech Economy? ECON 19(1), 106-116 (2011)

9. Kunstová, R.: Barriers and Benefits of Investments into Enterprise Content Management Systems. Organizacija 43(5), 205-213 (2010)

10. Kunstová, R.: Enterprise Content Management and Innovation. In: IDIMT-2010 Information Technology - Human Values, Innovation and Economy, Linz, Trauner, pp. 49-56 (2010)

11. Landis, J.R., Koch, G.G.: The measurement of observer agreement for categorical data. Biometrics 33(1), 159-174 (1977), http: / / jstor.org/stable/2529310 
12. Luftman, J.: Assessing Business-IT Alignment Maturity. Communications of the Association for Information Systems 4, Article 14, 1-50 (2000)

13. Maryška, M.: Model for Measuring and Analysing Costs in Business Informatics. In: The Eighth Wuhan International Conference on E-Business (CD-ROM), pp. 1-5. Alfred University Press, Sigillum (2009)

14. Novotný, O.: ICT Performance Reference Model in the Context of Corporate Performance Management. In: IDIMT-2009 System and Humans - A Complex Relationship, pp. 13-16. Trauner, Linz (2009)

15. Pour, J., Vorríšek, J.: Results of the survey of IS/ICT management in the Czech Republic. Systémová Integrace 18(1), 15-34 (2011)

16. Repa, V.: Building the Process-managed Organization by Means of Services. Journal of Systems Integration 2(2), 1-6 (2011) ISSN 1804-2724, http://si-journal.org/ index.php/JSI/article/view/87

17. Řepa, V.: Service-oriented Business Process Management. Funchal 06.10.2009 08.10.2009. In: IC3K 2009 (CD-ROM). INSTICC, Funchal, pp. 284-287 (2009) ISBN 978-989-674-013-9

18. Shen, C.W., Chou, C.C.: Business process re-engineering in the logistics industry: a study of implementation, success factors, and performance. Enterprise Information Systems 4(1), 61-78 (2010)

19. Vořríšek, J. et al.: Principles and Models of Enterprise IT Management, p. 446. Oeconomica, Prague (2008)

20. Voříšek, J., Feuerlicht, G.: The Impact of New Trends in the Delivery and Utilization of Enterprise ICT on Supplier and User Organizations. In: Amant, K. (ed.) IT Outsourcing: Concepts, Methodologies, Tools, and Application. Infromation Science Reference, pp. 2303-2316 (2009)

21. Vorríšek, J., Dunn, D.: Management of Business Informatics - Opportunities, Threats, Solutions. In: Systems Integration 2001, Prague, pp. 665-677 (2001), http: / / si.vse.cz/archive/index.asp?volume=2001

22. Voříšek, J., Jandoš, J., Feuerlicht, G.: SPSPR Model - Framework for ICT Services Management. Journal of Systems Integration 2(2), 3-10 (2011), http://www . si-journal.org/index.php/JSI/article/viewFile/85/58 